\title{
RESEARCH ON THE ORGANIZATIONAL CAPABILITY TO IDENTIFY AND ENHANCE AVAILABLE INTANGIBLE RESOURCES
}

\author{
Sebastian Emanuel STAN *, Camelia OPREAN-STAN** \\ *“Nicolae Bălcescu" Land Forces Academy, Sibiu, Romania \\ **"Lucian Blaga" University, Sibiu, Romania \\ office.sstan@gmail.com, camelia.oprean@ulbsibiu.ro
}

\begin{abstract}
This study aims to highlight the implications of intangible resource preponderance in all areas on the way of exercising management within Romanian organizations, respectively it will attempt to capture the respondents' ability of knowledge, identification and exploitation of intangible resources, and also, the way in which they consider it necessary to implement intangible resources management in their organizations. As a result, we have conducted a selective research among the factors involved in the knowledge and operationalization of these concepts (managers). The results of this research may be a reference for the concrete situation of the Romanian companies regarding the ability to know and operationalize the specific concepts of intangible resources management, but also a signal to all those involved or interested in this issue who will be able to give greater importance for the professionalization of those involved in intangible resources management at the level of organizations.
\end{abstract}

\section{Keywords: intangible resources, human, innovative, relational capital}

\section{Introduction}

The analysis of the degree of awareness of the Romanian managers about the imminent mutations taking place in the economic environment, with direct implications on the intangible resources management, materializes in the general (central) objective of the research.

From the point of view of the studies regarding the microeconomic and macroeconomic impact of intangible resources, the first analysis was conducted at the level of firms to explain their market value [1] [2], investors being eager to incorporate intangible resources in the evaluations of the firms they are interested in. In their research, the authors [3] argue that despite the importance of intangible resources at national level and the fact that they are an important factor in determining economic growth in the current knowledgebased economy, Romania's position in the international context regarding intangible assets is very weak, with many weak points in research and innovation performance compared to other EU Member States.

In connection with the main objective, the immediately derived objectives are outlined, which contribute to carrying out the research goal. These objectives have been based on the idea that, as already mentioned in the third chapter, the intangible resources of an organization may be interpreted both statically - as intangible resources that can be measured at any time, as well as dynamically - as intangible activities. The dynamic concept of intangible resources refers to three types of activities: firstly, the activities carried out by organizations with a view to acquiring 
new intangible resources through internal acquisition or production; secondly, activities to increase the value of available intangible resources; the third includes actions of evaluation, monitoring and control of intangible resources.

As a result, the derived objectives of the research are as follows:

$\mathrm{O}_{1}-$ Identification and capitalization of human capital

Human capital can be defined as what every employee brings to valorise creation processes, therefore, it is particularly important how managers are able to identify and capitalize on this type of capital within their organizations.

$\mathrm{O}_{2}$ - Analysis of human capital enablers

Such an analysis allows investigating the existing situation in the sample organizations regarding the types of intangible activities carried out in order to acquire new intangible resources associated with human capital, with the increase of their value and management.

$\mathrm{O}_{3}$ - Identification and capitalization of innovative capital

This objective allows highlighting the "organizational intellect" within the respondent firms, materialized in the innovative capital.

$\mathrm{O}_{4}-$ Analysis of innovation capital enablers

This analysis allows identifying the types of intangible activities carried out within the organizations in the sample in order to manage the intangible resources associated with the innovative capital, materialized in factors for their leveraging.

$\mathrm{O}_{5}-$ Identification and capitalization of structural capital

Starting from defining structural capital as representing the way in which employees are connected within the organization, respectively what remains when the employee leaves, it becomes very important to identify the way of capitalizing on this type of capital for the respondent organizations.
$\mathrm{O}_{6} \quad-$ Analysis of structural capital enablers

Since the structural capital enablers gain an indisputable importance in any organization, we wanted to evaluate how they create and appeal to such factors.

$\mathrm{O}_{7}-$ Identification and capitalization of relational capital

Starting from the fact that the value of an organization is given by the level and magnitude of the relationships it maintains with stakeholders, we wanted to highlight through this objective the main features of the existing relational capital within the organizations in the sample.

$\mathrm{O}_{8}-$ Analysis of relational capital enablers This objective becomes useful in investigating the situation existing within the organizations included in the sample with regard to the types of intangible activities carried out in order to acquire new intangible resources associated with human capital, with the increase of their value and management.

$\mathrm{O}_{9}-$ Analysis of intangible resources management performance

Through this goal, we wanted to highlight the way in which managers appreciate the performance of intangible resource management implemented at the level of their organizations.

\section{Methodology of Research}

In this study, secondary and primary research was used as a methodology. Secondary research consisted of documentation, drawing up the framework list of organizations relevant to the study. Through the use of certain publications, the list of companies in Sibiu County was drawn up, comprising the following types of information: field of activity, name of the company; address, telephone, fax, email, contact person. The list comprised 89 companies.

Applied primary research: as a direct research method, this involved the collection of data and information directly 
from their surveyor based on questionnaires. Thus, the method of collecting information was based on a questionnaire, which was administered to a sample of respondents. The survey carried out was undisciplined, the purpose being known from the beginning by the respondents.

Therefore, it is a partial, specially organized observation that was based on a voluntary filling in of the questionnaires that were sent, as mentioned above, directly or by online correspondence. It was intended to replace a large-scale observation that was virtually impossible. The administration of the questionnaires took place between September and November 2017.

\section{Analysis and Interpretation of Results} Objective 1 - Identification and Capitalization of Human Capital

Through this first research objective, we wanted to identify the extent to which certain assertions about human capital in organizations run by respondents are correct. In their opinion, the human capital issues that are complied with in the specific case of the organizations they run are the following:

- employees show earnestness at work (a score of 3.66 out of a maximum of 5);

- employees undertake their activity at work based on a set of moral and professional values (score of 3.46);

- employees have communication skills (3.29).

The following aspects were inappropriately punctuated by the respondent managers, thus materializing in negative aspects related to human capital (thus identifying certain gaps in the management of this type of capital):

- employees have the ability to think in the long-term (2.43);

- employees have problem-solving abilities (2.53);

- employees are proactive (2.71);

- existence of Professionals in the
Company (2.84).

\section{Objective 2 - Analysis of Human Capital Enablers}

Through this research goal, we wanted to identify the respondent managers' beliefs about the enablers of human capital existing in the organizations they run. Starting from the extent to which certain assertions about the existence of these enablers are correct, managers believe that the following factors related to the impulse of human capital are found in the specific case of the organizations in the sample:

- Discriminatory employee-related actions are avoided (a score of 3.79 out of a maximum of 5);

- The organization promotes transparent and accurate social dialogue (score of 3.63).

The following aspects were inappropriately punctuated by the respondent managers, thus materializing in negative aspects related to the existence of human capital enablers:

- There is a clear organizational policy on recognizing and rewarding innovation/ creativity outcomes (2.28);

- Employee satisfaction surveys are conducted (2.32);

- Labour ideas/ suggestions are requested and collected (2.41).

Objective 3 - Identification and Capitalization of Innovative Capital

Through this research goal, we wanted to identify the extent to which certain assertions about the innovative capital in the organizations run by the respondents are correct. In their opinion, the aspects of the innovative capital that are complied with in the specific case of the organizations they run are the following:

- In the organization, conversations and informal meetings are used to share knowledge (a score of 4.04 out of a maximum of 5);

- The organization has processes for using feedback from previous experience to improve future projects (score of 3.85).

The following aspects were inappropriately 
punctuated by the respondent managers, thus materializing in negative aspects related to the innovative capital (thus being identified some gaps in the management of this type of capital):

- The organization has processes to protect knowledge (2.15);

- The organization has technologies, specific processes, customer profiles or providers pledging as secrets (2.4).

Objective 4 - Analysis of Innovation Capital Enablers

Through this research goal, we wanted to identify the respondent managers' beliefs about the enablers of innovation capital existing in the organizations they run. Starting from the extent to which certain assertions about the existence of these enablers are correct, in the managers' opinion, the following factors related to the stimulation of the innovative capital are found in the specific case of the organizations in the sample:

- The organization makes investments in structuring business commercial information, customers, suppliers (a score of 3.15 out of a maximum of 5);

- Expenditure is planned for the management and protection of inventions and patents (score of 3.07).

The following aspects were inappropriately punctuated by the respondent managers, thus materializing in negative aspects related to the existence of innovative capital enablers:

- Competition control activities are carried out (2.34);

- The organization took initiatives and precautions to protect business secrets (2.53).

Objective 5 - Identification and Capitalization of Structural Capital

Through this research goal, we wanted to identify the extent to which certain assertions about structural capital in the organizations run by the respondents are correct. In their opinion, the structural capital issues that are complied with in the specific case of the organizations they run are as follows:

- There are archives and databases in the organization (a score of 3.41 out of a maximum of 5);

- The organization uses management systems (a score of 3.28).

The following aspects were inappropriately punctuated by the respondent managers, thus materializing in negative aspects related to the structural capital (thus some gaps being identified in the management of this type of capital):

- The business uses project management tools/ systems (2.4);

- The organization applies structured and codified procedures for its business activities (2.47);

- Projects based on interdepartmental cooperation are carried out (2.63).

\section{Objective 6 - Analysis of Structural Capital Enablers}

Through this research goal, we wanted to identify the respondent managers' beliefs about the enablers of structural capital existing in the organizations they run. Starting from the extent to which certain assertions about the existence of these enablers are correct, managers consider that the following factors related to the impulse of structural capital are found in the specific case of the organizations in the sample:

- Conditions are ensured for employees to perform their activity under full health and safety work conditions (a score of 4.07 out of a maximum of 5);

- The organization established the organizational framework and the related documents of human factor manifestation (a score of 3.93).

The following aspects were inappropriately punctuated by the respondent managers, thus materializing in negative aspects related to the existence of structural capital enablers:

- Investments are made in research and development and in new products (2.34);

- Investments are made in the internal 
structure (2.4);

- Improvements of methods and procedures are programmed (2.46);

- Costs are planned for the acquisition/ creation of the codified knowledge/ know-how (2.47).

Objective 7 - Identification and Capitalization of Relational Capital

Through this research goal, we wanted to identify the extent to which certain assertions about the relational capital in the organizations run by the respondents are correct. In their view, the aspects of the relational capital that are complied with in the specific case of the organizations they run are as follows:

- There are preferential supply agreements (a score of 3.66 out of a maximum of 5);

- The organization uses customer relationship management tools (a score of 3.07).

The following aspects were inappropriately punctuated by the respondent managers, thus materializing in negative aspects related to the relational capital (thus being identified some gaps in the management of this type of capital):

- The organization takes into account the interests of society, being responsible to employees, shareholders, the community and the environment (2.26);

- There are systems and initiatives to identify target consumers and specific visibility/ attraction/ marketing initiatives (2.29);

- The organization uses systems to select and qualify suppliers (2.57).

Objective 8 - Analysis of Relational Capital Enablers

Through this research goal, we wanted to identify the respondent managers' beliefs about the relational capital enablers existing in the organizations they run. Starting from the extent to which certain assertions about the existence of these enablers are correct, in managers' opinion, the following factors related to the impulse of relational capital are found in the specific case of the organizations in the sample:

- The organization performs sponsorship actions (a score of 3.53 out of a maximum of 5);

- Actions of monitoring, control, consumer satisfaction assessment are performed (score of 3.18).

The following aspects were inappropriately punctuated by the respondent managers, thus materializing in negative aspects related to the existence of relational capital enablers:

- Related costs are incurred: e.g. for monitoring competitors, competitive products (2.28);

- Initiative for establishing partnerships/ conventions are started up (2.37);

- Expenses for suppliers portfolio management are incurred (2.41);

- Improving communication with the mass media and the local community by organizing and conducting various events (e.g. "Open Doors Day") (2.46);

- Initiatives to improve image/ reputation are carried out (2.57);

- Investments are made for the development of new markets (2.62).

\section{Objective 9 - Analysis of Intangible} Resources Management Performance

Through this research goal, we wanted to identify the extent to which the respondent managers believe that certain assertions about the performance of intangible resource management in the organizations they run are correct. In their opinion, the aspects related to the intangible resources management performance that is complied with in the specific case of the organizations they manage are as follows:

- Customer satisfaction degree is high (a score of 3.74 out of a maximum of 5);

- The image and reputation of the organization compared to the sector average is better (score of 3.5).

The following aspects were inappropriately punctuated by the respondent managers, thus materializing in negative aspects related to the implementation of intangible 
resources management (thus identifying some gaps in the management of this type of resources):

- There are original and innovative ideas from employees (2.5);

- Labour force efficacy is high $(2,59)$;

- Labour force efficiency is high (2.6);

- Compared to major competitors, the organization is more innovative (2.65).

\section{Conclusions}

To sum up, from the analysis of the results of the scientific research carried out, we could notice that intangible resources management, as well as the knowledgebased management, are concepts not very well known by the Romanian managers. A good start to improve the application of intangible resources management at the organization level is to build a model that describes the process followed by organizations seeking to implement an intangible resources management system, which consists in three phases: the identification of critical intangible resources for creating value; the measurement of these resources through a set of indicators and, finally, the monitoring of the resources and intangible activities. [4]

However, the positive aspect is that there are managers who have noticed the increasing importance of intangible resources and knowledge in all spheres of activity, and they have managed to identify certain mutations perceived in their organizations. The main structural, organizational and management changes are:

- as a result of the increase in the share of knowledge held, there is an increase in the anticipatory and innovative role of management; Competitiveness through innovation becomes a rule; In this context, the creation of knowledge, underpinned by inventions, will be innovated;

- acquiring and gaining knowledge will be done through the learning processes of employees and the organization; thus, the development of intellectual capital can only be done by improving the learning processes;

- increasing the degree of intellectualization of the positions due to the emphasis placed on training. The company will truly become a teacher for its employees by using different training methods;

- efforts are being made to attract, motivate and retain knowledge-based employees in the firm. In this context, in the recruitment of human sources, emphasis will be placed on intelligence tests and on the "outside box" thinking;

- smart firms encourage staff initiatives, so employee involvement takes place in decision-making; the work will be organized on smaller, more differentiated work teams, organized according to tasks, showing flexibility and strong entrepreneurial spirit;

- maximum outsourcing of indirectly productive services to highly specialized companies;

- expanding the informational and technical revolution, thus facilitating the endowment of organizations with information technologies and the possibility of technology;

- creating, on an ever-increasing scale, knowledge-based inventions.

In these perspectives, the considerable danger that emerges is the moral wear and tear of knowledge. To avoid this loss, the measures that may be applied are:

- continuous professional development; advanced training courses; staff's selfstudy, lifelong learning, continuous information, participation in symposiums and conferences, learning by practice « learning by doing »;

- attracting human well-trained resources; widening employees' areas of competence; staff's motivation so as to stimulate generation of new ideas, transformation of ideas into products or 
services to be sold on the market;

- accumulation of information on: the most advanced knowledge into the field; the best performing technologies existing worldwide; the real costs of machines, materials etc.; avoiding the formation of unused stocks of knowledge.

\section{References}

[1] Malhotra, Y., Measuring knowledge assets of a nation: knowledge systems for development, Invited Research Paper Sponsored by the United Nations Department of Economic and Social Affairs. Keynote Presentation at the Ad Hoc Group of Experts Meeting at the United Nations Headquarters, New York City, 2003.

[2] Malhotra Y., Knowledge Management and New Organization Forms: A Framework for Business Model Innovation, Information Resources Management Journal, Jan-Mar, 13(1), 5-14, 2000.

[3] Oprean-Stan, C., Stan, S., Pele, A., The National Intangible Resources and Their Importance in the Current Knowledge-Based Economy, Management of Sustainable Development, 10 (2), 45-49, 2018.

[4] Stan, S., Oprean-Stan, C., Pele, A., A Proposal for an Intangible Resources Management System at the Organizational Level, Management of Sustainable Development, 10 (1), 17-21, 2018. 